Original Research Article

\title{
Efficacy and safety of formoterol versus montelukast as add on therapy in moderate persistent asthma
}

\author{
Mamta Rani ${ }^{1 *}$, Jarnail Singh ${ }^{1}$, Prem Parkash Gupta²
}

\begin{abstract}
${ }^{1}$ Department of Pharmacology, ${ }^{2}$ Department of T.B. and Respiratory Medicine, Pandit Bhagwat Dayal Sharma Post Graduate Institute of Medical Sciences, Rohtak, Haryana, India
\end{abstract}

Received: 24 February 2017

Accepted: 28 March 2017

\section{*Correspondence to:}

Dr. Mamta Rani,

Email: drkuldeep83@gmail.com

Copyright: (C) the author(s), publisher and licensee Medip Academy. This is an openaccess article distributed under the terms of the Creative Commons Attribution NonCommercial License, which permits unrestricted noncommercial use, distribution, and reproduction in any medium, provided the original work is properly cited.

\begin{abstract}
Background: From a pathophysiologic point of view, asthma treatment is directed toward the airway to effectively suppress inflammation, attenuate airway hyper responsiveness. Ideally, this in turn should translate into benefits in terms of symptom control, prevention of exacerbations, optimizing dyspnoea, along with patient safety.

Methods: This study was carried out at Department of Pharmacology and TB and Respiratory Medicine, Pt. BDS PGIMS, Rohtak, Haryana. The protocol was approved by institutional review board. Out of 60 OPD patients, group A (30) received inhaled budesonide $400 \mu \mathrm{g}$ and formoterol fumarate $6 \mu \mathrm{g}$ twice daily and group B (30) received oral montelukast $10 \mathrm{mg}$ once daily along with inhaled budesonide $400 \mu \mathrm{g}$ twice daily. All values were expressed as mean \pm SEM and comparison between both groups was done using unpaired $t$ test.

Results: Baseline PFT Values at 0 week and Improvement at 8 weeks were comparable between both groups with $\mathrm{P}$-value $>0.05$. In Group A both day time cough/wheeze score $(20.67 \pm 0.19$ to $11.23 \pm 0.37)$ and night time cough/wheeze score $(11.47 \pm 0.17$ to $4.27 \pm 0.21)$ reduced after 8 weeks treatment. Also in Group B daytime cough/ wheeze reduced from $(20.70 \pm 0.25)$ at 4 weeks to $(12.93 \pm 0.43)$ at end of 8 weeks. Modified Borg's dyspnoea score also decreased significantly $(3.13 \pm 0.11$ to $0.73 \pm 0.06)$ in Group A and $(3.16 \pm 0.14$ to $0.80 \pm 0.05)$ in Group B at end of 8 weeks and decrease was comparable in both groups (p value $>0.05$ ). Statistically there was no difference between two treatments as far as safety assessment was concerned. Most common ADRs reported were headache, asthenia and abdominal pain.

Conclusions: Montelukast seems clinically effective and safe in controlling asthma symptoms, PFT and improving dyspnoea. So montelukast can be reasonable and alternative therapeutic option as add on to inhaled ICS in moderate persistent asthma patients.
\end{abstract}

Keywords: Formoterol, Montelukast, Moderate persistent asthma

\section{INTRODUCTION}

Airway hyper responsiveness is a characteristic feature of asthma with reversible airflow obstruction caused by an array of inflammatory cells and cytokines. Inhaled corticosteroids (ICS) are effective in attenuating the underlying inflammatory process, with additional secondline preventive therapy being instituted for patients with persistent symptoms. ${ }^{1}$ The dose-response curve to inhaled corticosteroids is relatively flat, and there is increasing evidence that addition of another class of therapy (long- acting inhaled $\beta 2$-agonists, low dose theophylline, or antileukotrienes) may be preferable to increasing the dose of inhaled corticosteroids in patients with moderate-tosevere asthma. ${ }^{2}$

Moreover, there is a greater propensity for systemic adverse effects with increasing doses of inhaled corticosteroids, while patients may express a preference for treatment that avoids an excessive corticosteroid burden. ${ }^{3}$ 
Long acting $\beta_{2}$ agonists (LABAs) are helpful in improving asthma control and airway functions when inhaled corticosteroids alone are insufficient. ${ }^{4}$ LABAs, formoterol and salmeterol, do not exhibit in vivo antiinflamatory activity and thus not advocated for use as monotherapy in asthma. ${ }^{5,6}$ They are most effective when combined with ICS and this combination therapy is the preferred treatment when a standard dose of inhaled glucocorticosteroid alone fails to achieve control of asthma. They have steroid sparing effect and lead to better asthma control. But due to prolonged receptor occupancy, $\beta_{2}$ receptor becomes internalized and degraded. As a result, an attenuated response can be observed. In clinical setting of an acute asthma attack occurring in patients receiving LABAs, this may translate into failure to derive benefit from even high doses of inhaled salbutamol. ICS+ LABAs as single inhaler has better patient compliance. However, the main drawback is that adjusting the inhaled corticosteroids dose becomes less straightforward, with the potential consequence that patients may receive an unnecessary or insufficient dose for a prolonged period of time. ${ }^{7}$

LTRAs have bronchodilator and anti inflammatory properties in addition to attenuating airway hyperresponsiveness. ${ }^{8}$ LTRAs are effective orally and exert their effects following a single dose and tolerance to their broncho- protective effects has not been demonstrated. When compared to inhaled corticosteroids as monotherapy they are inferior in anti inflammatory action and clinical outcome measures., ${ }^{9,10}$

As per Global Initiative (GINA) guidelines 2014, for moderate asthma care at Step 3 ICS+LABA is the first option and ICS+ montelukast or theophylline is the alternate option, plus as needed SABA or low dose ICS+ formoterol. ${ }^{1}$ Still there are doubts and debates over the efficacy of montelukast as alternate to formoterol. Present study was planned to compare the efficacy and safety between montelukast and formoterol as add on to ICS in moderate persistent asthma.

\section{METHODS}

This was a prospective, open label, randomized, comparative clinical study conducted by the Department of Pharmacology and TB and Respiratory Medicine, Pt. B.D. Sharma PGIMS, Rohtak on 60 patients of either sex having moderate persistent asthma. Study protocol was approved by Institutional Review Board (IRB). All the patients were given all the appropriate information regarding study related procedures and an informed consent was obtained from all the patients enrolled for the study.

Patients aged 18 to 60 years having a history of at least 6 month of persistent asthma were eligible. They were further screened according to the inclusion criteria included forced expiratory volume in one second (FEV1) to forced vital capacity (FVC) ratio (FEV1/FVC) of less than $75 \%$ of predicted, FEV1 of $60-80 \%$ of predicted and an improvement of $12 \%$ or more in baseline FEV1 after using a $\beta_{2}$ agonist (salbutamol, 400 $\mu$ g). Patients were excluded if they had significant comorbidities, were receiving oral corticosteroids, LABAs, leukotriene antagonists or theophylline or had undergone an asthma exacerbation or lower respiratory tract infection within the four weeks prior to study entry, patients presented with acute life threatening/ near fatal asthma, with history of TB, bronchietasis, COPD or other non specific pulmonary diseases or history of bleeding disorders, hemorrhage and stroke or history of hypersensitivity to formoterol or montelukast. Pregnant and lactating women were also excluded.

Out of the 65 eligible patients (Figure 1) only 60 patients completed the study and the rest were lost to follow up (2 patients got shifted to bihar and 3 didnot come for $2^{\text {nd }}$ followup visit because of long distance and continued with same medicines). The eligible patients were randomly allocated in two groups - Group A received inhaled budesonide $400 \mu \mathrm{g}+$ formoterol fumarate $6 \mu \mathrm{g}$, twice daily and Group B with inhaled budesonide 400 $\mu \mathrm{g}$ twice daily+oral montelukast $10 \mathrm{mg}$ once daily for 8 weeks after run in period of 2 weeks in which both groups received inhaled budesonide $400 \mu \mathrm{g}$ twice daily. Patients were counselled about asthma and instructed how to use and clean metered dose inhaler to prevent blockage.

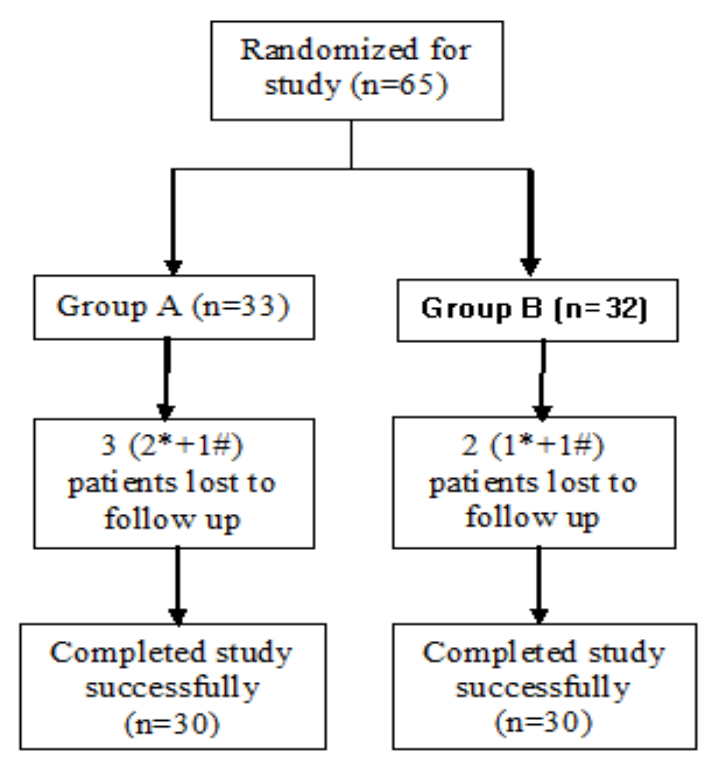

*Got shifted to bihar

\#Did not come for follow-up visit because of long distance and continued with same medication

Figure 1: Patients randomization, assignment and completion of study.

Baseline both demographic and clinical parameters were recorded in all the eligible patients like age, gender, history of duration of asthma, history of exacerbations in past, history of drug intake for asthma in past, history of 
drug allergies, smoking status, improvement in post bronchodilator $\mathrm{FEV}_{1}$ to check reversibility of airway obstruction, Borg's score and to establish severity of asthma- prebronchodilator $\mathrm{FEV}_{1}, \mathrm{FVC}, \mathrm{FEV}_{1} / \mathrm{FVC}$ and history of asthma symptoms etc. taken.

All the eligible patients were subjected to efficacy assessment by utilizing both primary and secondary outcome measures. Lung functions (PFT) as primary efficacy parameters were evaluated using a spirometer available in department of TB and Respiratory Medicine at time of screening, at 0 week, 4 and 8 weeks. Secondary efficacy parameters secondary efficacy parameters were evaluated using asthma symptoms diary consisting of day time cough/ wheeze (0-3 score), night time cough/ wheeze (0-3 score), shortness of breath (0-3 score), need

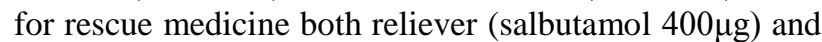
preventer (additional doses of study drugs apart from the doses recommended in study), other medications used other than study drugs during study duration, additional symptoms or triggering factors for symptoms at the end of 4 and 8 weeks.

Modified Borg's dyspnoea score (MBDS score) assessing breathing difficulties (0- Nothing at all and 10- maximal) was recorded at the time of screening i.e. in run in period, at baseline (0 week), 4 and 8 weeks.

Safety assessment was carried out in the both study groups at 4 and 8 weeks on the basis of any adverse effect reported by the patients.

\section{Statistical analysis}

Mean and standard error of mean (SEM) were calculated. Homogeneity of treatment groups for age, gender, height, weight, duration of illness, treatment history and chief complaints were analyzed by descriptive analysis. For quantitative data, paired ' $t$ ' test and repeated measure ANOVA whichever applicable was applied for intragroup analysis and independent ' $t$ ' test was applied for intergroup analysis of various parameters. $\mathrm{P}$ values less than 0.05 was taken as significant.

\section{RESULTS}

The baseline demographic characteristics of both treatment groups were the comparable (Table 1). Study showed that the number of patients visiting the hospital was more in the onset of winter than in summer as more no. of patients were enrolled for study during winter season.

Group A and group B were assessed for pulmonary function tests (PFT) at 0 week, 4 and 8 weeks. The mean values of MBDS, day time and night time cough/wheeze score, shortness of breath score and need for rescue medications were also evaluated.

\section{Table 1: Comparison of demographic characteristics in both groups.}

\begin{tabular}{|llll|}
\hline $\begin{array}{l}\text { Demographic } \\
\text { parameters }\end{array}$ & $\begin{array}{l}\text { Group A } \\
(\mathbf{n}=\mathbf{3 0})\end{array}$ & $\begin{array}{l}\text { Group B } \\
(\mathbf{n}=\mathbf{3 0})\end{array}$ & $\begin{array}{l}\mathbf{p} \\
\text { value }\end{array}$ \\
\hline Age (years) & $34.97 \pm 2.00$ & $39.60 \pm 2.19$ & 0.124 \\
\hline Female: male & $21 / 9$ & $22 / 8$ & 0.92 \\
\hline Height $(\mathrm{cms})$ & $161.80 \pm 1.29$ & $162.07 \pm 1.49$ & 0.893 \\
\hline Weight $(\mathrm{kg})$ & $57.97 \pm 2.45$ & $51.37 \pm 3.29$ & 0.113 \\
\hline Smoking H/O & 2 & 0 & 0.150 \\
\hline
\end{tabular}

All values are expressed as Mean \pm SEM

Both the drugs resulted in significant improvement in all the lung function tests i.e. FVC, FEV1/FVC and PEFR; and were found to be effective. As is evident from (Table 2), there was a significant improvement in $\mathrm{FEV}_{1}$ values over 8 weeks as compared to the baseline values at 0 week in both groups. Intragroup analysis showed that in group A marked improvement was seen at 4 weeks as compared to the value at 0 week and the improvement was sustained till 8 weeks.

Group B patients also showed a definite improvement at 4 weeks as compared to the baseline values and the improvement sustained till 8 weeks. Intergroup analysis revealed no significant difference in the improvement made in defined periods. Both treatment modalities show improvement in $\mathrm{FEV}_{1}$ to same extent.

Table 2: PFT values at different time interval in both group A and B.

\begin{tabular}{|c|c|c|c|c|}
\hline Time In & & $\mathrm{FEV}_{1}$ (liters) & PEFR (liters) & $\mathrm{FEV}_{1} / \mathrm{FVC}$ Ratio \\
\hline \multirow{3}{*}{0 week } & Group A & $1.91 \pm 0.05^{*}$ & $4.96 \pm 0.15^{*}$ & $0.698 \pm 0.009 *$ \\
\hline & Group B & $1.95 \pm 0.06^{*}$ & $4.99 \pm 0.18^{*}$ & $0.699 \pm 0.011 *$ \\
\hline & & $(\mathrm{P}-$ Value $=0.65)$ & $(\mathrm{P}-$ Value $=0.90)$ & $(\mathrm{P}-$ Value $=0.93)$ \\
\hline \multirow{3}{*}{4 weeks } & Group A & $2.18 \pm 0.07$ *\# & $5.88 \pm 0.24^{* \#}$ & $0.793 \pm 0.039^{* \#}$ \\
\hline & Group B & $2.19 \pm 0.06^{* \#}$ & $5.64 \pm 0.22^{* \#}$ & $0.791 \pm 0.040^{* \#}$ \\
\hline & & $(\mathrm{P}-$ Value $=0.99)$ & $(\mathrm{P}-$ Value $=0.47)$ & $(\mathrm{P}-$ Value $=0.96)$ \\
\hline \multirow{3}{*}{8 week } & Group A & $2.18 \pm 0.06^{* \#}$ & $5.81 \pm 0.22^{* \#}$ & $0.745 \pm 0.012^{* \#}$ \\
\hline & Group B & $2.37 \pm 0.16^{*}$ & $5.55 \pm 0.20^{* \#}$ & $0.757 \pm 0.015^{* \#}$ \\
\hline & & $(\mathrm{P}-$ Value $=0.30)$ & $(\mathrm{P}-$ Value $=0.39)$ & $(\mathrm{P}-$ Value $=0.55)$ \\
\hline
\end{tabular}

All values are expressed as Mean \pm SEM, ${ }^{*}$-value $<0.05, \#$ p-value $=>0.05$ 
Comparing the FEV1/FVC ratio within the two groups, it was found that in Group A there was significant improvement in the ratio at 4 weeks $(0.793 \pm 0.039)$ and also at 8 weeks $(0.745 \pm 0.012)$ as compared to baseline value $(0.698 \pm 0.009)$. Group B patients showed definite improvement at 4 weeks $(0.791 \pm 0.040)$ and 8 weeks $(0.757 \pm 0.015)$ in comparison to the baseline value

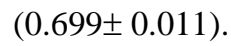

Intergroup statistical comparison of FEV1/FVC ratio (Table 2) showed that there was no significant difference at $0(\mathrm{p}=0.93), 4(\mathrm{p}=0.96)$ and 8 weeks $(\mathrm{p}=0.55)$ between the two groups. It shows that improvement was seen with both drugs i.e. formoterol and montelukast.

Regarding PEFR, in both the groups marked improvement (Table 2) was seen at 4 weeks (group $A=$ $5.88 \pm 0.24$, group $\mathrm{B}=5.64 \pm 0.22$ ) and 8 weeks (group $\mathrm{A}=$ $5.81 \pm 0.22$, group $\mathrm{B}=5.55 \pm 0.20)$ as compared to the baseline values (group $\mathrm{A}=4.96 \pm 0.15$, group $\mathrm{B}=$ $4.99 \pm 0.18)$.

Table 3: Modified Borg's Dyspnoea score between two groups at different time intervals.

\begin{tabular}{|llll|}
\hline Time & $\begin{array}{l}\text { Group A } \\
(\mathbf{n}=\mathbf{3 0})\end{array}$ & $\begin{array}{l}\text { Group B } \\
(\mathbf{n}=\mathbf{3 0})\end{array}$ & p value \\
\hline 0 week & $3.13 \pm 0.14^{*}$ & $3.16 \pm 0.14^{*}$ & $0.87(\mathrm{NS})$ \\
\hline 4 week & $1.10 \pm 0.10^{* \#}$ & $1.30 \pm 0.11^{* \#}$ & $0.18(\mathrm{NS})$ \\
\hline 8 week & $0.73 \pm 0.06 * \#$ & $0.80 \pm 0.05^{*} \#$ & $0.41(\mathrm{NS})$ \\
\hline
\end{tabular}

All values are expressed as Mean \pm SEM, *p-value $<0.05$, \# pvalue $=<0.05$

There was reduction in Borg's score (Table 3) after 4 weeks of therapy in both the groups as compared to baseline score. After 8 weeks of therapy, there was further reduction $(0.73 \pm 0.06$ in Group $A$ and $0.80 \pm 0.05$ in Group B). Decrease in MBDS score was statistically significant and also comparable in both treatment groups.

both the treatments improved the day time and night time cough/wheeze and shortness of breath score, however, formoterol was more effective in improving the symptoms of asthma that was statistically significant (Table 4).

There was statistically significant decrease in need for rescue medications (Table 4 ) in both groups i.e. none of patients in both groups reported need for rescue medication during 4-8 weeks periods.

Safety assessment was done using adverse drug monitoring proforma at 0-4, 4-8 week. The commonly reported adverse events were headache, asthenia and abdominal pain. Others were cough, nausea and vomiting, anxiety, arthralgia, leg pain, pruritis and nasal congestion. In Group $\mathrm{A}$, headache was reported in 5 patients during 0-4 weeks, 3 patients reported asthenia during 0-4 weeks, anxiety was reported in 3 patients during 0-4 weeks and 2 patients during 4-8 weeks, nausea was reported in 2 patients during 0-4 weeks and vomiting in one patient during same $0-4$ weeks period , 4 patients reported of nasal congestion 2 during 0-4 weeks and 2 during 4-8 weeks, abdominal pain was reported by 2 patients during 0-4 weeks, 3 patients reported of cough during 4-8 weeks, dizziness was reported in 3 patients during 4-8 weeks. 5 patients reported of arthralgia, 2 during 0-4 weeks and 3 during 4-8 weeks, pruritis in 4 patients during 4-8 weeks and 4 patients reported of leg pain during $\quad 4-8 \quad$ weeks.

Table 4: Secondary efficacy parameters at different time interval in both group $A$ and $B$.

\begin{tabular}{|llll|l|}
\hline Secondary efficacy parameters & Time interval & Group A & Group B & p- value \\
\hline \multirow{2}{*}{ Daytime cough/wheeze } & $0-4$ weeks & $20.67 \pm 0.19^{*}$ & $20.70 \pm 0.25^{*}$ & 0.92 \\
\hline \multirow{2}{*}{ Nighttime cough/wheeze } & $4-8$ weeks & $11.23 \pm 0.37^{*}$ & $12.93 \pm 0.43^{*}$ & 0.004 \\
\hline \multirow{2}{*}{ Shortness of breath score } & $0-4$ weeks & $11.47 \pm 0.17^{*}$ & $12.07 \pm 0.46^{*}$ & 0.23 \\
\cline { 2 - 5 } & $4-8$ weeks & $4.27 \pm 0.21^{*}$ & $5.43 \pm 0.48^{*}$ & 0.03 \\
\hline \multirow{2}{*}{ Need for rescue medication } & $0-4$ weeks & $24.13 \pm 0.28^{*}$ & $24.40 \pm 0.33^{*}$ & 0.54 \\
\cline { 2 - 5 } & $4-8$ weeks & $11.97 \pm 0.18^{*}$ & $13.67 \pm 0.43^{*}$ & 0.001 \\
\hline
\end{tabular}

All values are expressed as Mean \pm SEM, *p-value $<0.05$

In group B, 5 patients reported of headache during 0-4 weeks, 7 patients reported of asthenia 5 patients during 0 4 week and 2 patients during 4-8 weeks, 4 patients reported of nausea during $0-4$ weeks, one patient had vomiting during 0-4 weeks, abdominal pain was reported in 5 patients 2 during 0-4 weeks and 3 during 4-8 weeks.
The adverse events reported by patients in group A and B were of mild intensity.

Statistically both the treatments were equally well tolerated. Also there was no drop out in both groups due to adverse drug reactions reported. 


\section{DISCUSSION}

Overall the lung functions showed improvement in both the groups with maximum improvement seen at 4 weeks and that was sustained till 8 weeks study period. A number of studies have been conducted to compare the efficacy of LABAs and LTRAs using lung function tests. Studies by Fish et al, Ilowite et al, Ring dal et al, Nelson et al, Bjermer et al, Nelson et al and Storms et al have shown significant superiority in improvement in $\mathrm{FEV}_{1}$ and PEFR in patients of asthma put on salmeterol versus montelukast/ zafirlukast as add on treatment to ICS. ${ }^{11-17}$

Wilson et al observed equal improvement in PEFR and $\mathrm{FEV}_{1}$ with salmeterol and montelukast as add on to ICS. ${ }^{18}$ Kumaravel et al observed therapeutically equivalent increase in PEFR, FEV 1 and FVC with montelukast and formoterol in adult patients with moderate persistent asthma and declared that both treatments were therapeutically equivalent as add on to ICS. ${ }^{19}$

In the present study also montelukast and formoterol as add on to ICS were equally effective in improving the lung functions. The optimal improvement in lung functions was seen at 4 weeks in both groups and the improvement was sustained till 8 weeks.

Fish et al, Ilowite et al, Ringdal et al and Nelson et al observed that decrease in asthma symptoms (both day and night time) was more in salmeterol group as compared to montelukast/zafirlukast. ${ }^{11-14}$

Although the way of assessing the asthma symptoms was different in above mentioned studies, but results were consistent with present study results in which day time and nighttime cough/wheeze during 0-4 weeks of treatment in both the groups was comparable. The reduction in day time/ nighttime cough/wheeze during last 4-8 weeks may be due to symptom control with treatment.

The decrease in shortness of breath score during 4-8 weeks was observed in both the treatment groups but more decrease was in formoterol group. Nelson et al observed that decrease in shortness of breath score was more in salmeterol group as compared to montelukast. ${ }^{16}$

None of patients in both groups used reliever medication during 4-8 weeks. However, the comparison of difference in two groups was not statistically significant in two groups. Fish et al, Ilowite et al, Nelson et al and Bjermer et al, evaluated need for rescue medication as well as effect on exacerbations as efficacy parameter and observed no significant difference between the treatment groups. ${ }^{11,12,14,15}$

In the above mentioned studies there was decrease in need for rescue medication, also decrease in number of exacerbations. In our study also, there was no statistically significant difference in decreasing need for rescue medication between the two treatment groups.

Modified Borg's dyspnoea score was recorded at the time of screening i.e. before run in period, at baseline $(0$ week), 4 and 8 weeks. There was reduction in Borg's score after 4 weeks of therapy in both the groups as compared to baseline score. After 8 weeks of therapy, there was further reduction.

The difference was statistically significant when baseline Borg's scores were compared with scores at 4 and 8 weeks in both groups. The scores further improved at 8 weeks as compared to scores at 4 weeks and difference was statistically significant in both the groups. There was no significant difference in the values in two groups at all time periods during the study. This shows that both the treatments were equally effective in improving the Borg's score.

Kumaravel et al observed that improvement in Borg's score with montelukast and formoterol in adult patients with moderate persistent asthma was equal and declared both treatments are therapeutically equivalent as add on to ICS. ${ }^{19}$

There was no statistically significant difference between two groups when their safety profile was compared. Both the treatments were equally well tolerated. There was no drop out due to adverse drug reactions in both the treatment groups. Ringdal et al, Nelson et al reported that there were no clinically important differences between treatment groups with regard to adverse events i.e. adverse effects profile was comparable in both salmeterol and montelukast group as add on to inhaled fluticasone. ${ }^{13,16}$

\section{CONCLUSION}

The outcomes from this study suggest that the addition of montelukast in patients whose symptoms remain uncontrolled with inhaled budesonide is as effective as adding formoterol in improving lung functions, modified Borg's dyspnoea score and need for rescue medications. But improvement in daytime, night time cough/wheeze, shortness of breath score and improvement in quality of life was statistically more in formoterol group as compared to montelukast. Our study implies that the use of leukotriene receptor antagonist montelukast is an alternative and reasonable therapeutic option in moderate persistent asthma patients as add on to inhaled budesonide. Recently, GINA 2016 guidelines also suggest the use of montelukast as an alternative to formoterol as add on to ICS.

\section{Funding: No funding sources} Conflict of interest: None declared

Ethical approval: The study was approved by the Institutional Review Board (IRB), PGIMS, Rohtak, Haryana, India 


\section{REFERENCES}

1. Global Initiative for Asthma; 2014. Available from: http://www.ginasthma.org

2. Barnes PJ. Efficacy of inhaled corticosteroids in asthma. J Allergy Clin Immunol. 1998;102:531-8.

3. Lipworth BJ. Systemic adverse effects of inhaled corticosteroid therapy: a systematic review and metaanalysis. Arch Intern Med.1999;159:941-55.

4. Rodrigo GJ, Rodrigo C. The role of anticholinergics in acute asthma treatment: an evidence-based evaluation. Chest. 2002;121:1977-87.

5. Gardiner PV, Ward C, Booth H. Effect of eight weeks of treatment with salmeterol on bronchoalveolar lavage inflammatory indices in asthmatics. Am J Respir Crit Care Med. 1994;150:1006-11.

6. Calhoun WJ, Hinton KL, Kratzenberg JJ. The effect of salmeterol on markers of airway inflammation following segmental allergen challenge. Am J Respir Crit Care Med. 2001;163:881-6.

7. Currie GP, Daniel K, Lee C, Srivastava P. Long acting bronchodilator or leukotriene modifier as add on therapy to inhaled corticosteroids in persistent asthma? Chest. 2005;128:2954-62.

8. Currie GP, Lipworth BJ. Bronchoprotective effects of leukotriene receptor antagonists in asthma: a metaanalysis. Chest. 2002;122:146-50.

9. Jayaram L, Pizzichini E, Lemiere C, Man SF, Cartier A, Hargreave FE, et al. Steroid naive eosinophilic asthma: anti-inflammatory effects of fluticasone and montelukast. Thorax. 2005;60:100-5.

10. Duchaeme FM. Inhaled glucocorticoids versus leukotrienes receptor antagonists as single agent asthma treatment : systematic review of current evidence. BMJ. 2003;326:621-3.

11. Fish JE, Isarel E, Murray JJ, Emmett A, Boone R, Yancey SW, Rickard KA. Salmeterol powder provide significantly better benefit than montelukast in asthmatic patients receiving concomitant inhaled corticosteroid therapy. Chest. 2001;120:423-30.

12. Ilowite J, Webb R, Friedman B, Kerwin E, Bird SR, Hustad CM, et al. Addition of montelukast or salmeterol to fluticasone for protection against asthma attacks: a randomized, double- blind, multicenter study. Ann Allergy Asthma Immunol. 2004;92:641-8.

13. Ringdal N, Eliraz A, Pruzinec R, Weber HH, Mulder $\mathrm{PG}$, Akveld $\mathrm{M}$, et al. the salmeterol /fluticasone combination is more effective than fluticasone plus oral montelukast in asthma. Respir Med. 2003;97:234-41.

14. Nelson HS, Nathan RA, Kalberg C, Yancey SW, Rickard KA. Comparison of inhaled salmeterol and oral zafirlukast in asthmatic patients using concomitant inhaled corticosteroids. Med Gen Med. 2001;3:3.

15. Bjermer L, Bisgaard H, Bousquet J, Fabbri LM, Greening AP, Haahtela T, et al. Montelukast and fluticasone compared with salmeterol and fluticasone in protecting against asthma exacerbation in adults: one year, double blind, randomised, comparative trial. BMJ. 2003;327:891-7.

16. Nelson HS, Busse WW, Kerwin E, Church N, Emmett A, Rickard K, et al. Fluticasone propionate/ salmeterol combination provides more effective asthma control than low- dose inhaled corticosteroid plus montelukast. J Allergy Clin Immunol. 2000;106:1088-95.

17. Storms W, Chervinsky P, Ghannam AF, Bird S, hustad CM, Edelman JM. A comparison of effects of oral montelukast and inhaled salmeterol on response to rescue bronchodilation after challenge. Respir Med. 2004;98:1051-62.

18. Wilson AM, Dempsey OJ, Sims EJ, Lipworth BJ. Evaluation of salmeterol or montelukast as secondline therapy for asthma not controlled with inhaled corticosteroids. Chest. 2001;119:1021-6.

19. Kumaravel S, Kingston R, Sen S. Comparison of efficacy between long acting $\beta_{2}$ agonists (formoterol fumarate) and leukotriene receptor antagonists (montelukast) as add on therapy to inhaled corticosteroids (budesonide) in moderate persistent asthma. Arch Pharma Pract. 2014;5:61-5.

Cite this article as: Rani M, Singh J, Gupta PP.

Efficacy and safety of formoterol versus montelukast as add on therapy in moderate persistent asthma. Int $\mathbf{J}$ Basic Clin Pharmacol 2017;6:1420-5. 